\title{
Using mock interviews to prepare pharmacy students for professional placement: Results from a pilot study
}

\author{
Sam Kosari 1, Mary Bushell 1, Stephanie Mulhall 1, Jackson Thomas 1, Zubin Austin 2, Mark Naunton 1 \\ 1 Discipline of Pharmacy, Faculty of Health, University of Canberra, Bruce, Australia \\ 2 Leslie Dan Faculty of Pharmacy, University of Toronto, Ontario, Canada
}

\author{
Keywords \\ Pharmacy curriculum \\ Pharmacy student \\ Practice job interview \\ Mock job interview \\ Work-integrated learning

\section{Correspondence} \\ Sam Kosari \\ Discipline of Pharmacy \\ Faculty of Health \\ University of Canberra \\ Bruce \\ Australia \\ sam.kosari@canberra.edu.au
}

\begin{abstract}
Introduction: Mock interviews were introduced into a second-year pharmacy course with an embedded pharmacy placement. The aim was to prepare pharmacy students for interviews with possible preceptors when seeking community pharmacy placements. This study aimed to assess students' perspectives on the impact of this activity. Methods: Second year pharmacy students $(n=35)$ were provided with general interview guidance and participated in mock placement interviews conducted by community pharmacists. After participating in the mock interview, students were invited to complete two online questionnaires. The first questionnaire was completed following the mock interview and the second questionnaire was completed after students had secured professional placements. Both surveys contained multiple domains including student approach to placement, perceived impact of the mock interview on confidence and preparation, application of the feedback on their real-life interview, understanding employer priorities, linkage with the curriculum and overall student satisfaction. Results: Following the mock interview, most participants $(89.5 \%, n=17)$ indicated that they felt better prepared to approach a placement preceptor and for the interview process. All participants who completed the first questionnaire $(100 \%, n=19)$ agreed that the feedback following the mock interview was helpful. After securing a placement, more than half $(56.5 \%, n=13)$ indicated that they used the skillsets developed during the mock interview when approaching a placement preceptor. Conclusion: The inclusion of mock interviews in the pharmacy curricula was found beneficial and conducive to enhanced skills and confidence in students' career development.
\end{abstract}

\section{Introduction}

The professional experience placement, also known as work-integrated learning, is a crucial component of the Australian Bachelor of Pharmacy degree, a four-year degree leading to provisional registration as a pharmacist in Australia (Australian Pharmacy Council, 2021). Through an experiential learning approach, the professional placement facilitates the development of workplace competencies, enhances knowledge of the professional workplace and necessary professional attributes, and acts to bridge the gap between university learning and professional practice. In Australia, students may be tasked with identifying a suitable pharmacy preceptor with whom they will complete the required placement in a process that sometimes includes an interview. While these placements are central to the pharmacy degree, the skills required for successful placement searching and interviewing are not routinely included in the curriculum. To enable preparedness, the use of active learning approaches such as mock interviews can provide students with the opportunity to develop the skillsets required for the job search and interview process and more importantly to practice these skillsets in a safe environment (Bushell, 2015). In Australia, mock interviews are often used to prepare final year pharmacy students for 
internships. By comparison, in the United States, mock interviews are included as a component of programmes designed to improve success in obtaining competitive residency positions (Buckley et al., 2018; Caballero et al., 2017; Wolfgang, 2019). To date, there is a paucity of literature on the use of mock interviews to prepare students for work-integrated learning (professional placements). This study aimed to evaluate the inclusion of mock interviews to help prepare students for placement interviews and to assess student's perceptions of the usefulness of this activity.

\section{Methods}

In 2019, second-year Bachelor of Pharmacy students, enrolled in the unit, Dispensary and Logistics at the University of Canberra (UC), attended a preparatory education session delivered by staff at the UC Careers Center. This session aimed to enhance student knowledge about the generic job interview process and provide skills on how to write a good Curriculum Vitae (CV). The session was supplemented by education from pharmacist academics with information specific to the pharmacy interview process. Following this preparatory session students participated in a mock placement interview. The mock placement interview aimed to provide students with the opportunity to engage in an activity that simulated what may be expected of them when seeking out placement opportunities. Information was provided in the classes prior to the mock interview and students were instructed to bring their current $\mathrm{CV}$ to the interview for review. The mock interviews were designed to be realistic and were conducted by seven pharmacy employers who were registered pharmacists in the Australian Capital Territory, Australia. All interviewers had been involved in employing pharmacy students and/or interns through a real-life interview process, and had prior experience conducting interviews with pharmacy students seeking a placement under their preceptorship. Mock interviews were conducted in week four of a 13-week term. Each interview was conducted by one interviewer pharmacist and was approximately 15 minutes in duration. Each interviewer used the same question set for each student (Table I). The interview also incorporated a review of the student's CV. Following the completion of the mock interview, students were provided with verbal formative feedback based on their individual performance in the interview and the quality of their CV.

Participation in the study following the mock placement interview was voluntary and no payment or other incentive

\section{Table I: Interview question guide}

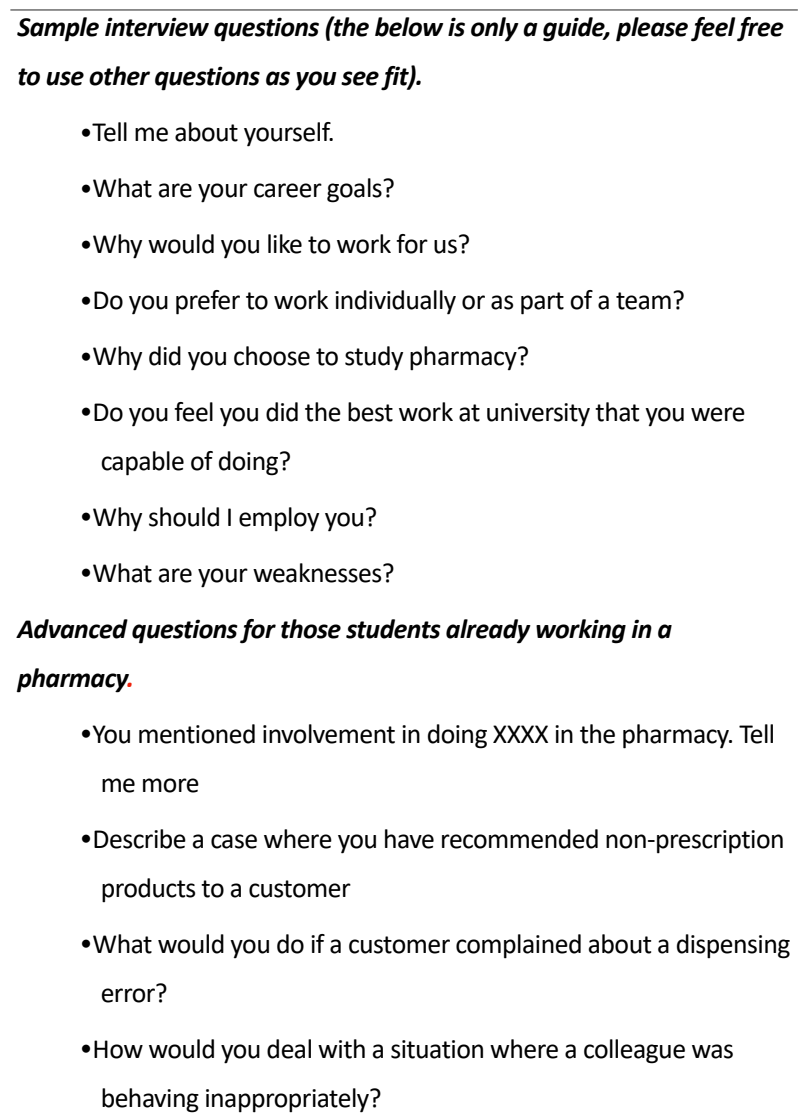

was provided. The study included two brief questionnaires developed by the authors of this paper (Table II and Table III). The questionnaires were distributed to the study participants online using Qualtrics. Questionnaires were face validated by both pharmacy academics and pharmacists employed in the community pharmacy setting. The first questionnaire aimed to assess student's perceived usefulness of the mock interview process and was completed. Students were invited to complete this questionnaire, within one week following the mock interview. The second questionnaire aimed to assess student perception of the usefulness of the mock interview after having successfully obtained a community pharmacy placement. The questionnaire was completed approximately two weeks after all students had submitted paperwork detailing they had an agreement in place with a preceptor to complete the required placement hours (150 hours). This was approximately six weeks after the first questionnaire. The successful completion of placement is required to pass the unit in which the placement is embedded.

Both surveys contained multiple domains including students' approach to obtaining their self-nominated work placement, perceived impact of the mock placement interview on building their confidence and preparation 
Table II: Questionnaire completed following the mock interview ( $=19)$.

\begin{tabular}{|c|c|c|c|c|c|c|c|c|c|c|}
\hline \multirow[b]{3}{*}{$\begin{array}{l}\text { Following the mock interview session today, I feel better } \\
\text { prepared to approach a placement preceptor }\end{array}$} & \multicolumn{10}{|c|}{ Responses, $n$ (\%) } \\
\hline & \multicolumn{2}{|c|}{ Strongly agree } & \multicolumn{2}{|c|}{$\begin{array}{l}\text { Somewhat } \\
\text { agree }\end{array}$} & \multicolumn{2}{|c|}{$\begin{array}{l}\text { Neither agree } \\
\text { nor disagree }\end{array}$} & \multicolumn{2}{|c|}{$\begin{array}{c}\text { Somewhat } \\
\text { disagree }\end{array}$} & \multicolumn{2}{|r|}{$\begin{array}{l}\text { Strongly } \\
\text { disagree }\end{array}$} \\
\hline & 6 & (31.6) & 11 & (57.9) & 2 & $(10.5)$ & 0 & (0.0) & 0 & $(0.0)$ \\
\hline $\begin{array}{l}\text { Following the mock interview, I feel better prepared for a real- } \\
\text { life interview process }\end{array}$ & 8 & $(42.1)$ & 9 & $(47.4)$ & 2 & $(10.5)$ & 0 & (0.0) & 0 & $(0.0)$ \\
\hline $\begin{array}{l}\text { Following the mock interview, I have a better understanding of } \\
\text { the expectations of me in a real-life interview process (e.g. } \\
\text { how to answer questions, writing CV or selection criteria) }\end{array}$ & 12 & $(63.2)$ & 7 & $(36.8)$ & 0 & $(0.0)$ & 0 & (0.0) & 0 & $(0.0)$ \\
\hline $\begin{array}{l}\text { The feedback I received from the interviewer following the } \\
\text { mock interview was helpful }\end{array}$ & 12 & $(63.2)$ & 7 & $(36.8)$ & 0 & $(0.0)$ & 0 & (0.0) & 0 & $(0.0)$ \\
\hline $\begin{array}{l}\text { The feedback I received from the interviewer following the } \\
\text { mock interview helped me to improve my CV }\end{array}$ & 11 & (57.9) & 7 & $(36.8)$ & 1 & $(5.3)$ & 0 & (0.0) & 0 & $(0.0)$ \\
\hline $\begin{array}{l}\text { I have identified specific areas where I can improve for future } \\
\text { real-life interviews }\end{array}$ & 10 & $(52.6)$ & 8 & $(42.1)$ & 1 & $(5.3)$ & 0 & (0.0) & 0 & $(0.0)$ \\
\hline $\begin{array}{l}\text { Following the mock interview, I have identified subject(s)/ } \\
\text { topic(s) within my pharmacy course curriculum that I need to } \\
\text { improve to meet my employers' expectations }\end{array}$ & 8 & $(42.1)$ & 7 & (36.8) & 4 & (21.1) & 0 & (0.0) & 0 & $(0.0)$ \\
\hline
\end{tabular}

Table III: Questionnaire completed following the professional placement search ( $n=23$ ).

\begin{tabular}{|c|c|c|c|c|c|c|c|c|c|c|}
\hline \multirow[b]{3}{*}{$\begin{array}{l}\text { I found the mock interview, conducted in week four, helpful in } \\
\text { finding a placement position }\end{array}$} & \multicolumn{10}{|c|}{ Responses, $n$ (\%) } \\
\hline & \multicolumn{2}{|c|}{ Strongly agree } & \multicolumn{2}{|c|}{$\begin{array}{l}\text { Somewhat } \\
\text { agree }\end{array}$} & \multicolumn{2}{|c|}{$\begin{array}{l}\text { Neither agree } \\
\text { nor disagree }\end{array}$} & \multicolumn{2}{|c|}{$\begin{array}{c}\text { Somewhat } \\
\text { disagree }\end{array}$} & \multicolumn{2}{|r|}{$\begin{array}{l}\text { Strongly } \\
\text { disagree }\end{array}$} \\
\hline & 5 & $(21.7)$ & 7 & $(30.4)$ & 5 & $(21.7)$ & 3 & (13.0) & 3 & (13.0) \\
\hline $\begin{array}{l}\text { I used the skills developed in the mock interview assessment } \\
\text { when approaching a preceptor }\end{array}$ & 6 & $(26.1)$ & 7 & $(30.4)$ & 4 & (17.4) & 2 & (8.7) & 4 & (17.4) \\
\hline $\begin{array}{l}\text { Following the mock interview session in week four, I feel better } \\
\text { prepared to approach a placement preceptor }\end{array}$ & 8 & $(34.8)$ & 9 & (39.1) & 2 & $(8.7)$ & 1 & (4.3) & 3 & (13.0) \\
\hline $\begin{array}{l}\text { The presentation by UC careers was helpful when approaching } \\
\text { a preceptor for a self-nominated placement }\end{array}$ & 7 & $(30.4)$ & 10 & $(43.5)$ & 5 & $(21.7)$ & 1 & (4.3) & 0 & 0.0 \\
\hline $\begin{array}{l}\text { Approaching a preceptor for a self-nominated placement has } \\
\text { improved my confidence for future real-life job seeking } \\
\text { interactions }\end{array}$ & 7 & $(30.4)$ & 10 & $(43.5)$ & 5 & $(21.7)$ & 1 & $(4.3)$ & 0 & 0.0 \\
\hline $\begin{array}{l}\text { Following the mock interview, I have identified subject(s)/ } \\
\text { topic(s) within my pharmacy course curriculum that I need to } \\
\text { improve in order to meet employers' priorities and } \\
\text { expectations }\end{array}$ & 11 & $(47.8)$ & 7 & $(30.4)$ & 4 & (17.4) & 1 & (4.3) & 0 & 0.0 \\
\hline
\end{tabular}

and the application of the formative feedback (they received at UC during the mock interview) in their reallife interview. The surveys also captured data on employer priorities, classroom curriculum linkages and overall student satisfaction with the teaching activity.

Each questionnaire included six questions that required respondents to rate their level of agreement on a 5point Likert scale (strongly agree to strongly disagree) and a free text question to explore the students' approach towards preparation for real-life placement interviews. Descriptive statistics were conducted. Free text responses were analysed to identify repeating themes. This study was approved by the University of Canberra Human Research Ethics Committee (approval number HREC 212) and all participants provided informed consent online before entering into the study.

\section{Results}

Of the 35 students in the course, a total of 19 students (54.3\%) completed the first survey following the mock placement interview. Approximately six weeks later, after successfully obtaining a community pharmacy 
placement, 23 students (65.7\%) completed the second survey.

\subsection{Survey 1: Findings after participating in a mock interview}

Prior to completion of the mock placement interview, 11 students $(57.9 \%)$ indicated that they had no prior experience with mock interviews, while the remaining eight students (42.1\%) reported previous experience participating in mock interviews. Approximately half of those who participated in the first survey were employed in a community pharmacy at the time of completing the mock interview $(52.6 \% n=10)$. Responses to a series of statements related to the mock placement interview are presented in Table II.

After the mock interview, most participants $(89.5 \%, \mathrm{n}=$ 17) agreed (strongly or somewhat) that they felt better prepared to approach a placement preceptor and for a real-life placement interview. All participants $(100 \%, n=$ 19) agreed (strongly or somewhat) that they had a better understanding of what would be expected during a reallife placement interview following the mock placement interview. They also indicated that the feedback they received during the mock interview was helpful. Almost all (94.7\%, $n=18$ ) agreed (strongly or somewhat) that the feedback they received would help them improve their CV. Similarly, most students $(94.7 \%, n=18)$ agreed that they had identified areas of improvement for future interviews. Most participants also agreed that they identified areas of the pharmacy curriculum that they could improve upon to better meet future employer's expectations $(78.9 \%, n=$ 15).

When participants were asked to list things that they were going to do to prepare for their placement, participants commonly reported improving their $\mathrm{CV}$, communication skills and course-related knowledge. When asked to list things that they would do to prepare for real-life interviews, participants commonly referred to improving their CV, gaining more knowledge, improving communication skills, clarifying professional goals, and presenting themselves in a professional manner.

\subsection{Survey 2: Findings after seeking a professional placement}

Most participants sought out a placement site and preceptor through a face-to-face interview $(69.6 \%, n=16)$, while about $21.7 \%(n=5)$ contacted a preceptor by phone and $8.7 \%(n=2)$ by email. Almost half $(47.8 \%, n=11)$ reported supplying their $\mathrm{CV}$ to the preceptor before finalising the placement agreement. Results from the second survey are summarised in Table III. Half of the participants $(52.1 \%, n=12)$ agreed (strongly or somewhat) that the mock interview had helped find a placement position, while $26.1 \%(n=6)$ disagreed (strongly or somewhat) that the mock interview had been helpful. Approximately half of the survey respondents $(56.5 \%, \mathrm{n}=$ 13) agreed that they used the skills developed in the mock interview when approaching a preceptor, four (17.6\%) responded neutral, and six (26.1\%) disagreed. Most $(73.9 \%, n=17)$ found the presentation by the UC Careers Center helpful. Most $(73.9 \%, n=17)$ reported that the process of approaching a preceptor had improved their confidence for future job seeking. The majority of respondents $(78.2 \%, n=18)$ identified areas of potential improvement in their knowledge base following the mock interview.

When participants were asked to describe how they prepared to approach a potential preceptor, responses varied. Most students reported some form of preparation, which usually included updating individual CVs. Some students described comprehensive preparation including gathering information related to their placement, revising their CVs and speaking to peers while others relied on a spontaneous approach, with little or no preparation reported.

\section{Discussion}

The authors evaluated the use of mock placement interviews as a component of coursework for second year undergraduate pharmacy students preparing for workintegrated learning. More than half of the cohort participated in mock interviews for the first time. The findings suggest that students considered participation in mock interviews a useful addition to their preparation for professional placements. Following the mock placement interviews, almost all participants regardless of employment status agreed that the experience improved their understanding of the interview process and that individual formative feedback received following the mock interview had been helpful. After securing a professional placement in the community, half of the respondents indicated that the skills developed during the mock interview had been of use as they sought a preceptor. There was a slight shift in the perceived degree of usefulness of the mock interviews reported in the second survey, however, the reasons for this are not clear. It may be related to the time gap between the second survey and when students had the actual interviews. Overall, both survey responses indicated the usefulness of mock 
interviews in various aspects of students' job interview skill.

The ability to communicate effectively during the interview process is crucial for pharmacy students seeking placement and pharmacy graduates seeking internships. Despite the importance of interview skills in securing professional placements and employment, activities that help students prepare for interviews early in the curriculum are not routinely included in the pharmacy curriculum (Buckley et al., 2018). While university-wide career support services are available at many institutions (Edwards et al., 2015) in this study, few students reported accessing the university careers centre. Hence, the inclusion of discipline specific career support within course curricula for pharmacy students may be of benefit.

There is value introducing interview skills early in the pharmacy degree programme. Interview preparation programmes tailored to pharmacy students seeking residency positions have been developed in the United States of America as graduates seek internships in highly competitive environments (Caballero et al., 2012; Stacy et al., 2013). These findings are consistent with previous research identifying the benefits of participation in mock interviews and other preparatory activities such as interview skills workshops (Bushell, 2015). Previous studies have found that pharmacy students who participated in preparatory activities were more successful at securing internships than those who did not participate (Bushell, 2015; Caballero et al., 2017) and their rate of success at securing positions was higher than the national average (Buckley et al., 2018). Furthermore, studies have also found that participation in preparatory activities and interview skills training was associated with improved interview related confidence among pharmacy students (Buckley et al., 2018; Bushell, 2015; Caballero et al., 2017; Fernández et al., 2019; Koenigsfeld et al., 2012; Powell et al., 2015).

The benefits of the mock interview may extend beyond the development of interview skills and confidence during the interview. In this study, interviews were conducted by pharmacy professionals which provided students with a unique opportunity to gain feedback from experienced professionals within the field. Feedback from the mock placement interview may help students identify opportunities for improvement and the authors found that most participants indicated that there were areas of learning that they could improve as a result of the teaching innovation. It also provided an early opportunity for networking with future employers.
Previous findings have indicated that the transition from student to professional can be challenging, with pharmacy students struggling with professional identity during this time (Noble et al., 2015). Further, opportunities to develop professional identity may be limited in the current pharmacy curriculum (Noble et al., 2014). The mock interview requires students to consider themselves in a professional role and may compel them to reflect on their knowledge, skills and professional goals.

The findings suggest that students initially considered the mock interview as a positive and modestly beneficial experience. This study also found that students secured professional placements through different modes of communication. While face-to-face interviews are common as students seek a professional placement, the process may vary widely based on different preceptors and workplaces. The lack of placement interview uniformity likely impacted the perceived value of the activity for some students. For example, students who completed the mock placement interview and were then required to interview for a real placement interview valued the experience compared with students who approached a placement site and preceptor, who did not require an interview to be offered a placement opportunity. Further research is needed to quantify the different ways students obtain placements, and what proportion of students self-nominate placements and are required to conduct an interview (either face to face or virtual). Overall, it appears that strategies (employed in this study) to enhance students' interview skills are well received and found to improve confidence and career growth and development. These skills are likely transferable when students' complete interviews for future internship positions. This may lead to improved job interview skills in an often highly competitive environment.

\section{Conclusion}

This study is novel as it evaluated the introduction of mock interviews early in the curriculum, to prepare pharmacy students for placement. To the authors knowledge the value of this has not been previously published. The findings showed that pharmacy students who participated in a mock interview prior to seeking a professional placement in the community found the mock interview was beneficial and led to improved job interview skills and confidence. The use of mock interviews was considered as a useful addition to the course curriculum to facilitate student skill development as they prepare for professional 
placement interviews and assist with their future employment opportunities. Further, participation in the mock interview may help students reflect on their learning and career goals. These findings support the ongoing inclusion of mock interviews in the unit Dispensary and Logistics and may be of use to other pharmacy educators.

\section{Limitations and future directions}

The authors evaluated the use of mock interviews in a small sample of undergraduate students from a single unit in an Australian university which limits our ability to generalise these findings beyond this sample. One limitation is that while the mock placement interview activity itself was not voluntary, the completion of evaluation surveys was. The researchers do not know if the pharmacy students who did not complete the voluntary survey need more support to prepare them for placement.

Many students reported that they wanted to improve their 'communication skills'. However, specific communication skills that require improvement were not elicited. For example, it was unknown whether students wanted to improve non-verbal communication, such as eye contact, hand shaking, or verbal communication skills. Future research is needed to identify the specific learning needs of students to improve preparedness for placement interviews. While the interviews were not videotaped there may be value in recording the mock interviews and providing a copy back to students for their own learning.

There may be an opportunity to further tailor this experience to the needs of students given that some participants did not find that the skills developed during the mock interview were necessary when seeking a preceptor. Future research may also explore student's perspectives on professional placement in order to identify whether there are additional preparatory activities that could be incorporated into pharmacy education.

\section{References}

Australian Pharmacy Council. (2020). Accreditation standards for pharmacy programs in Australia and New Zealand

Buckley, K., Karr, S., Nisly, S.A., \& Kelley, K. (2018). Evaluation of a mock interview session on residency interview skills. Currents in Pharmacy Teaching and Learning, 10(4), 511-516
Bushell M.A.J., Moore L, Hendry, E., \& Adams A,. (2015). Mock interviews for internships: Improving pharmacy student preparedness using formative assessment Pharmacy Education, 15(1), 159 - 161

Caballero, J., Benavides, S., Clauson, K.A., Hardigan, P.C., Steinberg, J.G., Gauthier, T.P., Sherman, E.M., Seamon, M.J., Valdes, J., \& Thomas, J.E. (2017). Role of residency interview preparatory activities as a determinant on pharmacy residency match rates. Journal of Pharmacy Practice, 30(2), 219-222

Caballero, J., Benavides, S., Steinberg, J.G., Clauson, K.A., Gauthier, T., Borja-Hart, N.L., \& Marino, J. (2012). Development of a residency interviewing preparatory seminar. American Journal of Health-System Pharmacy, 69(5), 400-404

Edwards, D., Perkins, K., Pearce, J., \& Hong, J. (2015). Work integrated learning in STEM in Australian universities. Canberra: Office of Chief Scientist \& Australian Council for Educational Research, 1-120

Fernández, E.V., Reid, J.C., Woodard, L.M., Holdford, D.A., Gravatt, L.A.H., \& Donohoe, K.L. (2019). Implementation of an interviewing skills workshop for pharmacy students. Currents in Pharmacy Teaching and Learning, 11(3), 277-286

Koenigsfeld, C.F., Wall, G.C., Miesner, A.R., Schmidt, G., Haack, S.L., Eastman, D.K., Grady, S., \& Fornoff, A. (2012). A faculty-led mock residency interview exercise for fourth-year doctor of pharmacy students. Journal of Pharmacy Practice, 25(1), 101-107

Noble, C., Coombes, I., Nissen, L., Shaw, P.N., \& Clavarino, A. (2015). Making the transition from pharmacy student to pharmacist: A ustralian interns' perceptions of professional identity formation. International Journal of Pharmacy Practice, 23(4), 292-304

Noble, C., Coombes, I., Shaw, P.N., Nissen, L.M., \& Clavarino, A. (2014). Becoming a pharmacist: the role of curriculum in professional identity formation. Pharmacy Practice, 12(1)

Powell, A.D., Yip, S., Hillman, J., Larson, S., Cooley, J., \& Davis, L.E. (2015). Preparing pharmacy graduates for interviews: A collaborative statewide mock interview session to improve confidence. Currents in Pharmacy Teaching and Learning, 7(5), $684-690$

Stacy, Z.A., Yancey, A.M., High, A.E., Brooks, A.D., \& Burke, J.M. (2013). Description of a formalized residency preparation program. Currents in Pharmacy Teaching and Learning, 5(2), 140-145

Wolfgang, K.W. (2019). A novel and comprehensive design of mock residency interviews for fourth-professional year doctor of pharmacy students. Currents in Pharmacy Teaching and Learning, 11(9), 956-960 